\title{
Management of Non-Pain Symptoms in Pediatric Palliative Care
}

\author{
Stefan J. Friedrichsdorfa, b John J. Collins ${ }^{a}$

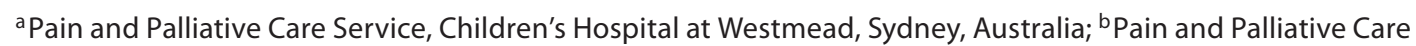 \\ Department, Children's Hospitals and Clinics of Minnesota, Minneapolis, Minn., USA
}

\author{
Key Words \\ Pediatric palliative care $\cdot$ Symptom management $\cdot$ Child • \\ Terminal care $\cdot$ Dyspnea $\cdot$ Nausea and vomiting $\cdot$ Death \\ rattle $\cdot$ Seizure control $\cdot$ Muscle spasm $\cdot$ Anorexia
}

\begin{abstract}
The majority of children dying from a life-limiting condition suffer from distressing symptoms during their last weeks of life. The provision of current state-of-the-art symptom control is paramount for any health care professional working with dying children, but treatment guidelines are sparse. This article reviews the management of integrative and pharmacological therapies for acute seizure control, anorexia, death rattle, dyspnea, nausea and vomiting, and muscle spasm during the end-of-life period of children and teens. Several myths and misconceptions have led to inadequate symptom control in children with a terminal disease. A dying
\end{abstract}

The authors have made extensive efforts to ensure that treatments, drugs and dosage regimens in this article are accurate and conform to the standards accepted at the time of the publication. However, changes in information through continuing research and clinical experience and the possibility of human error warrant that the authors do not accept any responsibility for any loss or damage arising from actions or decisions based on information in this article: the ultimate responsibility for the treatment of patients and interpretation of published material lies with the medical practitioner. There are standard on-line references for current dosing information and one of these should be consulted.
(C) 2007 S. Karger AG, Basel

$1011-7571 / 07 / 0167-0003 \$ 23.50 / 0$

Fax +4161306 1234

E-Mail karger@karger.ch

www.karger.com
Accessible online at:

www.karger.com/mpp child is often highly symptomatic, and providing professional integrative and pharmacological symptom relief is one of the many precincts of pediatric palliative care.

Copyright $\odot 2007$ S. Karger AG, Basel

\section{Introduction}

The management of distressing symptoms during the end-of-life period of children is of utmost importance for professionals engaged in pediatric palliative care. Not only is it important from a humanitarian viewpoint, but it is also apparent that the memory of unrelieved symptoms in dying children may be retained in the memory of parents and siblings many years after the child has died [1]. It will not be possible for the sick children and their families to negotiate the domains of psychological and spiritual care if physical symptoms have not been adequately treated. This article provides a short review of the current management of distressing non-pain symptoms in pediatric palliative care. For much more comprehensive information refer to the Oxford Textbook of Palliative Care for Children [2].

\section{Symptom Management}

Common symptoms during the last week of life were reported in 5 studies for a group of 445 children in total, the majority suffering from central nervous system tu- 
Table 1. Common pediatric symptoms during end-of-life care

\begin{tabular}{|c|c|c|c|c|c|c|c|}
\hline Pain & 134 & 16 & 140 & 21 & 84 & 395 & 84 \\
\hline Lack of appetite & no data & 10 & 106 & 28 & 84 & 228 & $73^{*}$ \\
\hline Fatigue & 86 & 21 & 79 & 20 & 100 & 297 & 63 \\
\hline Constipation & 94 & 8 & 58 & 13 & 51 & 224 & 47 \\
\hline
\end{tabular}

* Symptom not assessed by Dangel, prevalence by Drake et al., Goldman, Hongo et al., and Wolfe et al. only.

mors and other malignant diseases, but also from neurodegenerative or muscular diseases, including pain, lack of appetite, fatigue, vomiting, dyspnea and constipation (table 1). In addition to that, children with life-limiting conditions may also present with drooling, difficulties in swallowing, feeding difficulties, noisy breathing ('death rattle'), seizures, agitation, anxiety, and spasticity according to case reports and our own experiences.

\section{Respiratory Problems}

\section{Dyspnea}

Dyspnea refers to the subjective sensation that breathing has become unpleasant, rather than an objective observation that it has become fast or difficult or that the saturation has dropped. Treating dyspnea is often challenging, as the underlying pathophysiological basis often remains unclear (e.g. when there is no primary cause like respiratory muscle dysfunction in children with muscle dystrophy). Dyspnea is a multidimensional symptom, which must be approached from different angles.

Causes of dyspnea which may be treatable - according to the condition of the individual child - should be ruled out and include infection, acidosis, fluid overload, anemia, lung metastasis, pulmonary embolism, pleural effusion, cardiac failure, pain, and anxiety. Whether a positive-pressure ventilation mask may be beneficial in children with neuromuscular diseases has to be discussed with the affected child and the family in each individual case.

Supportive measures are often effective in decreasing the sensation of breathlessness and include finding the most comfortable position in bed or a chair, improving the air circulation (many children improve with a fan blowing in their face or opening the window), and decreasing the room temperature. A calm approach is usually very beneficial, as the vicious circle 'dyspnea causes anxiety, anxiety causes dyspnea' may be quite disruptive. Breathing exercises, relaxation, guided imagery, story telling, and hypnosis are powerful tools in managing anxiety in the older and responsive child.

There are currently no randomized controlled trials for the management of dyspnea in pediatric palliative care. The application of an opioid is the main pharmacological therapy recommended in managing dyspnea. The effect is based on several mechanisms: opioids decrease the perception of breathlessness, decrease the ventilatory drive by decreasing the responsiveness to hypercapnia and hypoxia, and decrease oxygen consumption [3].

Morphine has also a vasodilatory activity, from which children with heart failure and/or pulmonary hypertension may benefit. Opioid-naïve children would be started with half the analgesic dose and then titrated up to effect (table 2). We usually use a continuous infusion of an opioid (usually morphine, fentanyl, hydromorphone or methadone), intravenous or subcutaneous with a bolus (frequently by means of patient-controlled analgesia pumps), but the oral (and the occasionally used transdermal) route proved to be effective as well. Adult studies show some positive results with nebulized morphine in terminal dyspnea [4]. First case reports of nebulized morphine show little or mild beneficial effects in children [5]. Since nebulized morphine may cause a bronchospasm, it should be used with caution.

Benzodiazepines are useful anxiolytics and are commonly used as an adjunct to opioids in the management of dyspnea in children. The mechanism of effect is not 
Table 2. Respiratory drug therapy in pediatric palliative care

\begin{tabular}{|c|c|c|c|}
\hline Drugs & Starting dose & $\begin{array}{l}\text { Route of } \\
\text { administration }\end{array}$ & Side effects/caution \\
\hline \multicolumn{4}{|l|}{ Dyspnea } \\
\hline Morphine & $\begin{array}{l}0.2 \mathrm{mg} / \mathrm{kg} \text { every } 4 \mathrm{~h} \text { plus } 0.1-0.2 \\
\mathrm{mg} / \mathrm{kg} \text { every } 1 \mathrm{~h} \text { as needed }\end{array}$ & per os & titrated to effect, usual opioid side effects \\
\hline Midazolam & $\begin{array}{l}1 \mu \mathrm{g} / \mathrm{kg} / \mathrm{min} \text { plus } 1 \mu \mathrm{g} / \mathrm{kg} \\
\text { every } 15 \mathrm{~min} \text { as needed }\end{array}$ & intravenous/subcutaneous & titrated to effect \\
\hline \multicolumn{4}{|l|}{ Noisy breathing/death rattle } \\
\hline Glycopyrronium & $5-10 \mu \mathrm{g} / \mathrm{kg}$ three times a day & intravenous/subcutaneous & \\
\hline
\end{tabular}

TSS = Total soluble solids

totally clear, but seems to be based on the depression of hypoxia or hypercapnia ventilatory responses and alteration of the emotional response to dyspnea [6]. Lorazepam, diazepam and midazolam are frequently prescribed in the treatment of pediatric dyspnea. Excessive respiratory secretions may be a dose-related side effect of all benzodiazepines.

The role of oxygen is controversial. Many children with dyspnea in their terminal phase may not find oxygen helpful and may become agitated by the mask or nasal prongs. The goal must be to improve the subjective perception of breathlessness, and not the alteration of objective findings (e.g. oxygen saturation or blood gases). The interaction between the child and the parents should be taken into consideration as well. Quite often it is very important for the parents 'to do something', even when that may not be medically beneficial.

Other medications less frequently used in managing dyspnea in children include nebulized saline to loosen mucus, bronchodilators for bronchospasm, diuretics for fluid overload, and packed cells for anemia.

\section{Noisy Breathing/Death Rattle}

Most children with a life-limiting disease display in their terminal phase noisy breathing or a death rattle.
This may be very distressing for the family, and they should be advised about this prior to the end-of-life period of their child. The mechanism is usually based on the inability to swallow saliva with subsequent pooling in the pharynx, rather than excessive secretions. The child is usually unconscious and does not suffer from the death rattle. Hence an indication to treat may only be given if the child appears distressed or the family cannot tolerate the sometimes extremely noisy breathing. Anticholinergic drugs to dry secretion and suctioning may be effective. Anticholinergics should be used with caution though, as they thicken secretion, and may make it more difficult to cough up mucus and therefore may cause distress for the sick child and increase the risk for pneumonia. We prefer glycopyrronium, which does not cross the blood-brain barrier and therefore rarely causes central side effects. Hyoscine hydrobromide (scopolamine) is active on the central nervous system and is an alternative that may be applied by a patch. Excessive application of fluids parenterally or via the nasogastric/ percutaneous endoscopic gastrostomy tube to a dying child often causes fluid overload and may worsen the death rattle. 


\section{Neurological Problems}

Dying children with neurological conditions should always be cared for collaboratively with a pediatric neurologist. It would be far beyond the scope of this article to discuss the treatment of seizures and muscle spasms in depth, but we would like to stress a few practical issues during terminal care.

\section{Seizures}

Children with a neurodegenerative disorder may have a long history of multiple fits and may be on a multitude of antiepileptics. Parents are usually relaxed and knowledgeable about seizures and how to treat them. Worsening seizure control in a patient with an underlying seizure disorder may indicate either disease progression or factors related to anticonvulsant dose, class, or administration, which should be reviewed by the pediatric neurologist.

For the family of a child without preexisting epilepsy even brief generalized seizures can be very distressing, and the family should be prepared for such a possibility. Fits during the terminal phase of a child's illness may be due to brain tumors (primary, metastatic or meningeal lesions), raised intracranial pressure, intracranial hemorrhage, metabolic disturbances (hypoglycemia, hyponatremia, hypocalcemia, hepatic encephalopathy), infection, fever, and hypoxia. Those causes must be excluded, as treatment directed at the primary courses may be appropriate while anticonvulsant therapy is implemented.

The administration of a benzodiazepine is usually the most effective acute treatment of seizures (e.g. diazepam p.r. $0.5-0.7 \mathrm{mg} / \mathrm{kg}$; <15 kg: $5 \mathrm{mg},>15 \mathrm{~kg}$ : $10 \mathrm{mg}$; may be repeated after 5-10 $\mathrm{min}$ ). Compared to the practice in some European countries like Germany and France, the rectal application of drugs to children is far less socially accepted in many English-speaking countries. Buccal midazolam (intravenous solution used buccally: 0.1-0.3 $\mathrm{mg} / \mathrm{kg}$ per dose, max. $15 \mathrm{mg}$ ) has been shown to be at least as effective as rectal diazepam [7] and has become the preferred treatment for acute seizures in Australia, and also among pediatric patients with life-limiting and terminal conditions in the United States. Intravenous midazolam or phenobarbitone may be considered.

\section{Muscle Spasms}

Muscle spasm is a common problem in children with neurodegenerative disorders. Again, close collaboration with the pediatric neurologist is paramount, as muscle spasm may be due to pain or may be epileptic tonic spasms. Children who have repeated muscle spasms are often very distressed. The early involvement of a physiotherapist may be useful and advice on seating, positioning, moving and handling may assist in preventing positioning that can cause muscle spasm. Pharmacological agents, which may be beneficial, include baclofen (starting dose $0.2 \mathrm{mg} / \mathrm{kg}$ three times a day, max. $5 \mathrm{mg}$ p.o., may be increased every 3 days to $1 \mathrm{mg} / \mathrm{kg}$ three times a day, max. $50 \mathrm{mg}$ p.o.), which may worsen a preexisting epilepsy, oral diazepam, which may be sedating, dantrolene, which may cause drowsiness, or Botox, which is injected into affected muscles. It must be borne in mind that increased muscle tone and spasm may be the only thing that allows a child to sit or stand up [8].

\section{Gastrointestinal Problems}

\section{Nausea and Vomiting}

The majority of children suffer from nausea and vomiting during the terminal phase (table 1). These occur when the vomiting center in the brain is activated by any of the following: cerebral cortex (e.g. anxiety), vestibular apparatus, chemoreceptor trigger zone, vagus nerve, or by direct action on the vomiting center. Treatable causes need to be ruled out and include gastrointestinal problems [e.g. ascites, constipation, reflux (ileus)], drug side effects (antibiotics, anticholinergics, digoxin, nonsteroidal anti-inflammatory drugs, opioids, palliative chemotherapy, steroids, tricyclic antidepressants), infections (e.g. gastroenteritis), metabolic dysfunction (e.g. hypercalcemia, renal failure), brain metastasis/raised intracranial pressure, pain, radiotherapy, hypogeusia/dysgeusia, pharynx irritation (e.g. candida infection), and anxiety.

Integrative and supportive management of nausea and vomiting may be particularly helpful and include - considering the underlying disease and the responsiveness of the child - offering small and tasty food portions, frequent application of drinks the child likes, avoiding smells the child dislikes, reduction of anxiety (e.g. psychological counseling, relaxation, breathing techniques, hypnosis, occupational therapy, music therapy) [9-11], acupuncture [12], and good mouth care.

Most randomized controlled trials in children regarding the pharmacological treatment of nausea and/or vomiting are in children with cancer. It may or may not be valid to extrapolate from these to patients with nonmalignant conditions. A rational treatment regime according to the assumed pathophysiology should be initi- 
Table 3. Antiemetic drug therapy in pediatric palliative care

\begin{tabular}{|c|c|c|c|c|}
\hline 5-HT3 antagonists & ondansetron & $\begin{array}{l}5 \mathrm{mg} / \mathrm{m}^{2} \text { body surface } \\
\text { twice a day, } \max .8 \mathrm{mg} / \text { dose }\end{array}$ & per os, intravenous & $\begin{array}{l}\text { may cause constipation, } \\
\text { overdose may cause } \\
\text { nausea }\end{array}$ \\
\hline $\begin{array}{l}\text { Dopamine antagonists/ } \\
\text { prokinetic drugs }\end{array}$ & metoclopramide & $\begin{array}{l}0.15-0.3 \mathrm{mg} / \mathrm{kg} \text { four times } \\
\text { a day }\end{array}$ & $\begin{array}{l}\text { per os, intravenous, } \\
\text { subcutaneous, per } \\
\text { rectum }\end{array}$ & $*$ \\
\hline $\begin{array}{l}\text { Dopamine antagonists/ } \\
\text { prokinetic drugs/ } \\
\text { neuroleptic drugs }\end{array}$ & haloperidol & $5-25 \mu \mathrm{g} / \mathrm{kg}$ every $8-12 \mathrm{~h}$ & $\begin{array}{l}\text { per os, subcutaneous, } \\
\text { intravenous }\end{array}$ & $\begin{array}{l}\text { extrapyramidal side } \\
\text { effects* }\end{array}$ \\
\hline $\begin{array}{l}\text { Antihistamines/ } \\
\text { anticholinergics }\end{array}$ & cyclizine & $1 \mathrm{mg} / \mathrm{kg}$ three times a day & $\begin{array}{l}\text { per os, intravenous, } \\
\text { subcutaneous }\end{array}$ & * \\
\hline Antihistamines & dimenhydrinate & $1-2 \mathrm{mg} / \mathrm{kg}$ every $6-8 \mathrm{~h}$ & $\begin{array}{l}\text { per os, intravenous, } \\
\text { per rectum }\end{array}$ & $\begin{array}{l}\text { max. daily dose } 75 \mathrm{mg} \\
\text { (2-6 years), } 150 \mathrm{mg} \\
\text { (6-12 years) }\end{array}$ \\
\hline Anticholinergics & & $\begin{array}{l}1 \text { mg patch }>10 \text { years, } \\
\text { change every } 72 \mathrm{~h}\end{array}$ & transdermal & \\
\hline Corticosteroids & dexamethasone & $0.1-1 \mathrm{mg} / \mathrm{kg}$ every $6-8 \mathrm{~h}$ & $\begin{array}{l}\text { per os, intravenous, } \\
\text { subcutaneous }\end{array}$ & $\begin{array}{l}\text { cushingoid effects with } \\
\text { long-term use, gastric } \\
\text { irritation, mood } \\
\text { instability, poor } \\
\text { control of blood sugar }\end{array}$ \\
\hline Benzodiazepines & lorazepam & $25-50 \mu \mathrm{g} / \mathrm{kg}$ every $6-8 \mathrm{~h}$ & per os, intravenous & $\begin{array}{l}\text { drowsiness, max. } \\
1 \mathrm{mg} / \text { dose }\end{array}$ \\
\hline
\end{tabular}

* Prokinetic drugs not in combination with anticholinergic drugs or amitriptyline.

ated. Combining supportive measures with one or more drugs may be appropriate. A prokinetic drug must not be used in combination with an anticholinergic. Prokinetics are metabolized in a cholinergic pathway and anticholinergic drugs (as well as cyclizine, Buscopan and amitriptyline) block the prokinetic effect [13]. Antiemetic drugs used in pediatric palliative care are shown in table 3 .

5-HT3 antagonists like ondansetron [14, 15], tropisetron $[16,17]$, and granisetron [18] proved to be very effective in chemotherapy-induced nausea and vomiting in children. We find ondansetron to be helpful in treating nausea in many children with terminal conditions.

Dopamine antagonists, especially metoclopramide, but also domperidon and haloperidol, are prokinetics which may induce a dyskinetic syndrome. This is a rare, but for the affected child and family very frightening side effect, which then has to be treated with biperiden.
There are yet little pediatric data to support the application of neurokinin-1 antagonists as antinausea agents in children [19].

Histamine-1 receptor antagonists/acetylcholine (muscarine) receptor antagonists like cyclizine are commonly used to treat nausea and vomiting in children with a terminal condition, especially when caused by raised intracranial pressure. Cyclizine is an over-the-counter drug in Switzerland, the UK, and New Zealand but has to be ordered through the international pharmacy in some countries. Although cyclizine is commonly used, especially in the UK, no pediatric randomized controlled trials have yet been published. Other drugs in this class include levomepromazine and promethazine.

The main component of cannabis, delta-9-tetrahydrocannabinol, has antiemetic properties [20]. There are few pediatric studies, but doses of dronabinol up to $0.15 \mathrm{mg} /$ $\mathrm{kg}$ twice a day seem to be effective in adults [21]. 
Corticosteroids seem to be very effective in relieving nausea and vomiting for a short period, if caused by a brain tumor/metastasis, by reducing the surrounding edema. Corticosteroids also inhibit the synthesis of prostaglandins, which may have a role in nausea. We prefer to administer dexamethasone, which has by comparison a low mineralocorticoid effect, only over a few days due to the significant side effects of corticosteroids.

Other drugs which may be useful in managing nausea and vomiting in children with terminal diseases include benzodiazepines (act on the cerebral cortex) and the somatostatin analogue octreotide (for bowel obstruction, when an operation is no longer feasible) $[22,23]$.

An antiemetic step-by-step drug approach has not yet been evaluated in pediatrics. Treating nausea and vomiting in the dying child may be very challenging and a combination of different antiemetic drugs alone will often not be successful, if integrative methods have not been included and if the child's anxiety has not been thoroughly addressed.

\section{Anorexia and Feeding Issues}

Children with progressive degenerative conditions commonly develop feeding difficulties during the course of their disease. Anorexia is common during the end-oflife period of most children with a life-limiting disease. Treatment of reversible conditions (including pain, nausea, constipation, drug side effects, depression, esophagitis, and gastritis) and presentation of small, tasty meals may improve the intake. Many children with a neurodegenerative disease will receive a percutaneous endoscopic gastrostomy tube to enable feeding. Feeding is an extremely important issue for all families of affected children, and family counseling should concentrate on the comfort of the child to reduce tension and stress in relation to the feeding difficulties. Nonpharmacological methods may be particularly helpful.

Many children do not show any interest in food during their last weeks of life. The gestagen megestrol acetate (5-10 $\mathrm{mg} / \mathrm{kg}$ once daily, p.o.) seems to increase the appetite and body weight of severely ill children according to some studies [24-26]. The side effects of this drug include glucose intolerance and adrenal gland suppression.

The application of corticosteroids to increase appetite cannot be recommended due the significant side effects (e.g. cosmetic changes and mood instability).

\section{Conclusion}

Several myths and misconceptions have led to inadequate symptom control in children with a terminal disease. Some health providers and parents believe opioids in the management of pain and dyspnea should only be administered as a last resort, to avoid drug addiction. They have not understood that tolerance plus physical dependence is NOT addiction. An even greater fear might be that the death of the child will be hastened by the commencement of morphine. The opposite is often true. It is a common experience of pediatric palliative care teams around the world that commencing opioids for symptom relief improves the quality of life of affected children. And those who feel better usually live longer.

A dying child is often highly symptomatic, and providing professional integrative and pharmacological symptom relief is one of the many domains of pediatric palliative care.

\section{References}

1 Worden JW, Monahan JR: Caring for bereaved parents; in Armstrong-Daily A, Zarbock S (eds): Hospice Care for Children, ed 2. Oxford, Oxford University Press, 2001, pp 137-156.

2 Goldmann A, Hain RDW, Liben S (eds): Oxford Textbook of Palliative Care for Children. Oxford, Oxford University Press, 2006.

3 Tyler LS: Dyspnea in palliative care patients; in Lipman AG, Jackson KC 2nd, Tyler LS (eds): Evidence-Based Symptom Control in Palliative Care. New York, Haworth Press, 1999, pp 109-128.
4 Westphal CG, Campbell ML: Nebulized morphine for terminal dyspnea: a treatment option in chronic obstructive pulmonary disease or end-stage congestive heart failure. Am J Nurs 2002;102:11-15.

5 Cohen SP, Dawson TC: Nebulized morphine as a treatment for dyspnea in a child with cystic fibrosis. Pediatrics 2002;110:e38.

6 Chan KS, Sham MMK, Tse DMW, Thorsen $\mathrm{AB}$ : Palliative medicine in malignant respiratory diseases; in Doyle D, Hanks G, Cherny N, Calman K (eds): Oxford Textbook of Palliative Medicine, ed 3. Oxford, Oxford University Press, 2004, pp 587-618.
7 Scott RC, Besag FM, Neville BG: Buccal midazolam and rectal diazepam for treatment of prolonged seizures in childhood and adolescence: a randomised trial. Lancet 2002;353: 623-626.

8 Jassal SS: Basic Symptom Control in Paediatric Palliative Care: The Rainbows Children's Hospice Guidelines, ed 4. Loughborough, Leicestershire, Rainbows Children's Hospice, 2002.

-9 Cotanch P, Hockenberry M, Herman S: Selfhypnosis as antiemetic therapy in children receiving chemotherapy. Oncol Nurs Forum $1985 ; 12: 41-46$ 
10 Jacknow DS, Tschann JM, Link MP, Boyce WT: Hypnosis in the prevention of chemotherapy-related nausea and vomiting in children: a prospective study. J Dev Behav Pediatr 1994;15:258-264.

11 Zeltzer L, LeBaron S, Zeltzer PM: The effectiveness of behavioral intervention for reducing nausea and vomiting in children and adolescents receiving chemotherapy. J Clin Oncol 1984;2:683-690.

12 Vickers AJ: Can acupuncture have specific effects on health? A systematic review of acupuncture antiemesis trials. J R Soc Med 1996; 6:303-311.

13 Twycross R, Back I: Nausea and vomiting in advanced cancer. Eur J Palliat Care 1998;5: 39-44.

$\checkmark 14$ Stiakaki E, Savvas S, Lydaki E, Bolonaki I, Kouvidi E, Dimitriou H, Kambourakis A, Kalmanti M: Ondansetron and tropisetron in the control of nausea and vomiting in children receiving combined cancer chemotherapy. Pediatr Hematol Oncol 1999;16:101108.

15 Brock P, Brichard B, Rechnitzer C, Langeveld NE, Lanning M, Soderhall S, Laurent $\mathrm{C}$ : An increased loading dose of ondansetron: a north European, double-blind randomised study in children, comparing $5 \mathrm{mg} /$ $\mathrm{m}^{2}$ with $10 \mathrm{mg} / \mathrm{m}^{2}$. Eur J Cancer 1996; 32A:1744-1748.
16 Ozkan A, Yildiz I, Yuksel L, Apak H, Celkan T: Tropisetron (Navoban) in the control of nausea and vomiting induced by combined cancer chemotherapy in children. Jpn J Clin Oncol 1999;29:92-95.

17 Uysal KM, Olgun N, Sarialioglu F: Tropisetron in the prevention of chemotherapy-induced acute emesis in pediatric patients. Turk J Pediatr 1999;41:207-218.

18 Aksoylar S, Akman SA, Ozgenc F, Kansoy S: Comparison of tropisetron and granisetron in the control of nausea and vomiting in children receiving combined cancer chemotherapy. Pediatr Hematol Oncol 2001;18:397406.

19 Smith AR, Repka TL, Weigel BJ: Aprepitant for the control of chemotherapy induced nausea and vomiting in adolescents. Pediatr Blood Cancer 2005;45:857-860.

20 Hall W, Degenhardt L: Medical marijuana initiatives: are they justified? How successful are they likely to be? CNS Drugs 2003;17: 689-697.

21 Grotenhermen F, Bialas B: Cannabinoide in der Medizin. Rheinisches Arztebl 2003;12: 21-22.

22 Mercandante S, Spoldi E, Caraceni A: Octreotide in relieving gastrointestinal symptoms. Palliat Med 1993;7:295-299.

23 Khoo D, Hall E, Motson R, Riley J, Denman $\mathrm{K}$, Waxman J: Palliation of malignant intestinal obstruction using octreotide. Eur J Cancer 1994;30A:28-30.

24 Eubanks V, Koppersmith N, Wooldridge N, Clancy JP, Lyrene R, Arani RB, Lee J, Moldawer L, Atchison J, Sorscher EJ, Makris CM: Effects of megestrol acetate on weight gain, body composition, and pulmonary function in patients with cystic fibrosis. J Pediatr 2002;140:439-444.
25 Clarick RH, Hanekom WA, Yogev R, Chadwick EG: Megestrol acetate treatment of growth failure in children infected with human immunodeficiency virus. Pediatrics 1997;99:354-357.

26 Marchand V, Baker SS, Stark TJ, Baker RD: Randomized, double-blind, placebo-controlled pilot trial of megestrol acetate in malnourished children with cystic fibrosis. J Pediatr Gastroenterol Nutr 2000;31:264-269.

27 Dangel T: Domowa opieka paliatywna nad dziecmi w Polsce. Warsaw, Department of Palliative Care, Institute for Mother and Child, 2001.

28 Drake R, Frost J, Collins JJ: The symptoms of dying children. J Pain Symptom Manage 2003;26:594-603.

29 Goldman A: Symptoms and suffering at the end of life in children with cancer - correspondence. N Engl J Med 2000;342:19971999.

30 Hongo T, Watanabe C, Okada S, Inoue N, Yajima S, Fujii Y, Ohzeki T: Analysis of the circumstances at the end of life in children with cancer: symptoms, suffering and acceptance. Pediatr Int 2003;45:60-64.

31 Wolfe J, Grier HE, Klar N: Symptoms and suffering at the end of life in children with cancer. N Engl J Med 2000;342:326-333. 